\title{
Cowden syndrome and Lhermitte-Duclos disease in a family: a single genetic syndrome with pleiotropy?
}

CRC Human Cancer Genetics Research Group,

Department of

Pathology,

University of

Cambridge,

Tennis Court Road,

Cambridge CB2 1QP,

UK

C Eng

B A J Ponder

Division of Medical

Oncology,

Division of Cancer

Epidemiology and

Control,

Dana-Farber Cancer

Institute,

Department of

Medicine,

Harvard Medical

School,

Boston, USA

C Eng

South West Thames

Regional Genetics

Service,

St George's Hospital

Medical School,

Cranmer Terrace,

London, UK

V Murday

South East Thames Regional Genetics

Centre,

Guy's Hospital,

St Thomas' Street

London, UK

$S$ Mohammed

S V Hodgson

ICRF Clinical

Oncology Unit,

Guy's Hospital,

St Thomas' Street,

London, UK

MA Chaudray

I S Fentiman

CRC Academic Unit of Radiotherapy and Oncology,

The Royal Marsden

Hospital,

Hospital,

Sutton, Surrey SM2

SPT, UK

R A Eeles

Section of Molecular

Carcinogenesis,

Institute of Cancer

Research,

15 Cotswold Road,

Sutton, Surrey SM2

5NG, UK

5NG,

R A Eeles

Correspondence to

Dr Eng.

Received 18 August 1993 Revised version accepted for publication publication 1994

Charis Eng, Victoria Murday, Sheila Seal, S Mohammed, Shirley V Hodgson, Murid A Chaudary, Ian S Fentiman, Bruce A J Ponder, Rosalind A Eeles

\begin{abstract}
Cowden syndrome is an autosomal dominant condition of multiple hamartomas. Patients with this phakomatosis have an increased risk of breast cancer and thyroid tumours. Lhermitte-Duclos disease is usually a sporadic condition of cerebellar ganglion cell hypertrophy, ataxia, mental retardation, and self-limited seizure disorder. We describe a three generation family with Cowden syndrome and Lhermitte-Duclos disease. Karyotyping performed on the peripheral lymphocytes of the proband and her affected mother showed a 46,XX complement. Single strand conformational polymorphism analysis failed to show any germline p53 mutations as a cause of the syndrome in this family.
\end{abstract}

\section{(f Med Genet 1994;31:458-461)}

Cowden syndrome, an autosomal dominant genodermatosis of multiple hamartomas involving all three germ layers, is associated with an increased risk of breast cancer and thyroid tumours. ${ }^{1}$ The aetiology of this syndrome is unclear; neither the susceptibility locus nor the chromosomal location is known. Since the first description of Rachel Cowden, the patient after whom the syndrome is named, ${ }^{2}$ several publications have added to the clinical features associated with this syndrome. ${ }^{13-7}$ Lhermitte-Duclos disease (LDD) is a rare, usually sporadic, condition in which the normal cells of the cerebellum are replaced by a hamartomatous mass of hypertrophic ganglion cells. ${ }^{7}$ We report a three generation family with Cowden syndrome and LDD: one family member had Cowden syndrome and histologically documented LDD, two family members had Cowden syndrome and a syndrome clinically consistent with LDD, and another family member may have LDD but his whereabouts are unknown. Cytogenetic and p53 mutation analyses are described.

\section{The proband}

A 14 year old girl (III.4, fig 1) had a seven month history of multiple, large masses involving both breasts. Biopsy showed giant fibroadenomas. She has no other symptoms, including haematochezia or melaena. Her IQ has been assessed to be approximately 70 and she attends a special school for the educatio- nally subnormal. Her head circumference is $62 \mathrm{~cm}$ ( $>99$ th centile). Physical examination showed multiple $2-5 \mathrm{~mm}$ perioral and mucocutaneous verrucous papillae and tricholemmomata on the right malar area, right arm (fig 2A), and left anterior chest; a scrotal tongue consisting of multiple papillomatous lesions on the dorsum and frenulum (fig 2B); four café au lait spots (each $>5 \mathrm{~mm}$ ) with irregular margins on her thighs and additional freckling on her groins and upper thighs; and bilateral large, heavy breasts in which multiple solid masses could be palpated, the largest measuring $3 \mathrm{~cm}$ in diameter. Thyroid examination was unremarkable. She has mild cerebellar ataxia.

\section{The family}

The patient's maternal grandfather (I.1, fig 1) had well documented Cowden syndrome and biopsy proven Lhermitte-Duclos disease. ${ }^{8} \mathrm{He}$ had prominent mucocutaneous papillomatosis, acral keratoses, a plantar angiolipoma, and nodular reactive lymphoid hyperplasia of the right lung. Neurological features were cerebellar ataxia and increased intracranial pressure. A biopsy showed LDD and caroticocavernous fistula. However, he was not mentally retarded and was able to work as a travel agent. He died of a stroke from an intracerebellar haemorrhage in his late $50 \mathrm{~s}$.

The proband's mother (II.4, fig 1 ) is a 37 year old woman who has a history of resected

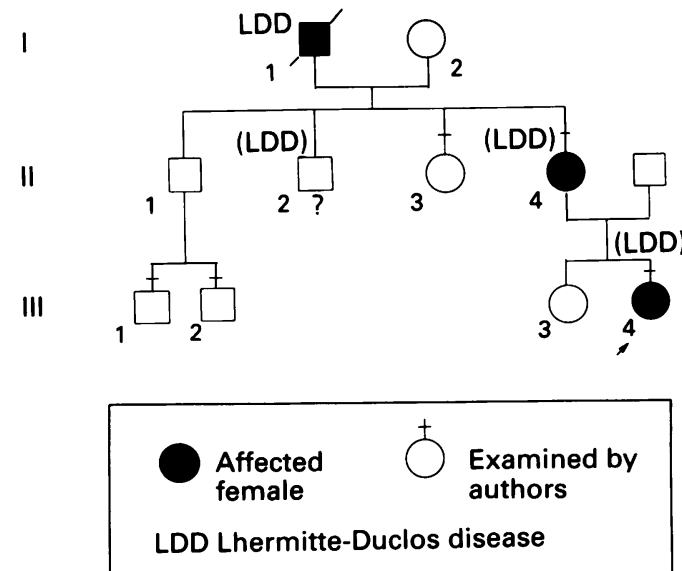

Figure 1 Pedigree of the family with Cowden syndrome and Lhermitte-Duclos disease. LDD in parentheses denotes that the diagnosis was made on clinical criteria only (see text). 


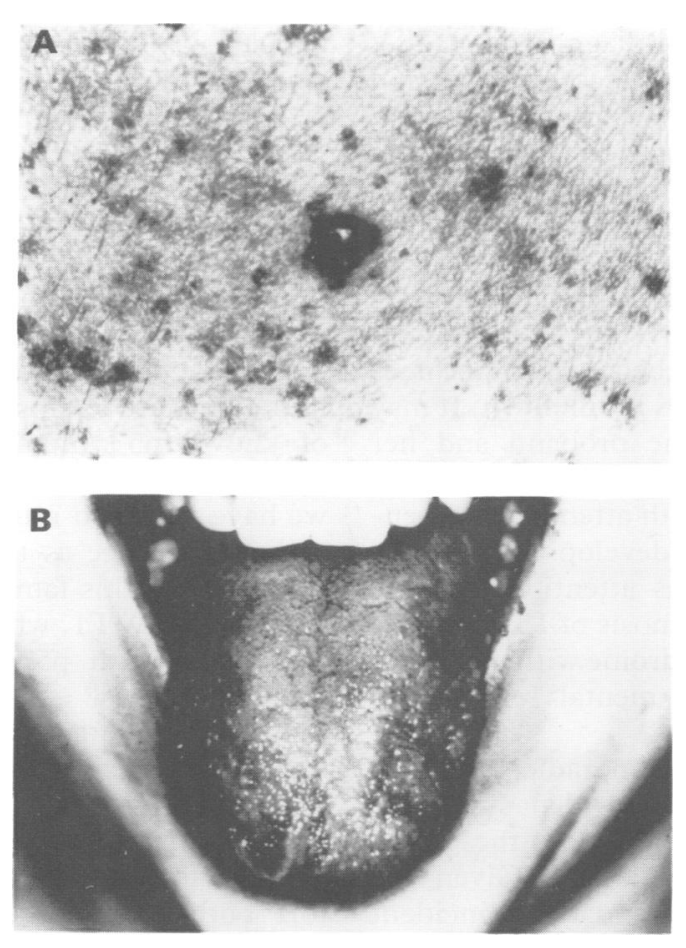

Figure 2 The proband with the pathognomonic features of Cowden syndrome showing verrucous papilla on the proband's right arm $(A)$ and scrotal tongue consisting of papillosis $(\boldsymbol{B})$.

periareolar fibroadenomas of the left breast and grand mal seizures in her teens. At the age of 30, she experienced intermittent upper abdominal swelling. Evaluation with computerised tomography and angiography showed focal nodular hyperplasia of the liver. Her head circumference was $62 \mathrm{~cm}$ ( $>99$ th centile). Examination of the skin and mucous membranes showed a few mucocutaneous papillae and acral keratoses, but no scrotal tongue. She has mild to moderate bilateral dysmetria and sways from side to side when walking in tandem, although she does not have truncal ataxia, dysarthria, or Romberg's sign. She had mild mental retardation with an IQ estimated to be 70 . Thyroid examination was unremarkable. Mammography showed bilateral fibroadenomas (fig 3). Magnetic resonance imaging of the brain showed megencephaly but no mass lesions in the cerebellum.

The proband's uncle, II.2, was described by the family to have macrocephaly and mental retardation. Although he may have LDD as well, we are unable to document this as the family is unaware of his whereabouts. To his family's knowledge, he has no children. The patient's sister (III.3), aunt (II.3), an uncle (II.1), and his children (III.1, III.2) are unaffected. II.1 has not consented to a medical examination.

\section{Cytogenetic and molecular genetic studies}

Chromosome analyses of cultured lymphocytes from the proband and her mother showed a $46, \mathrm{XX}$ karyotype. In addition, no germline mutation in exons $1-11$ of the p53

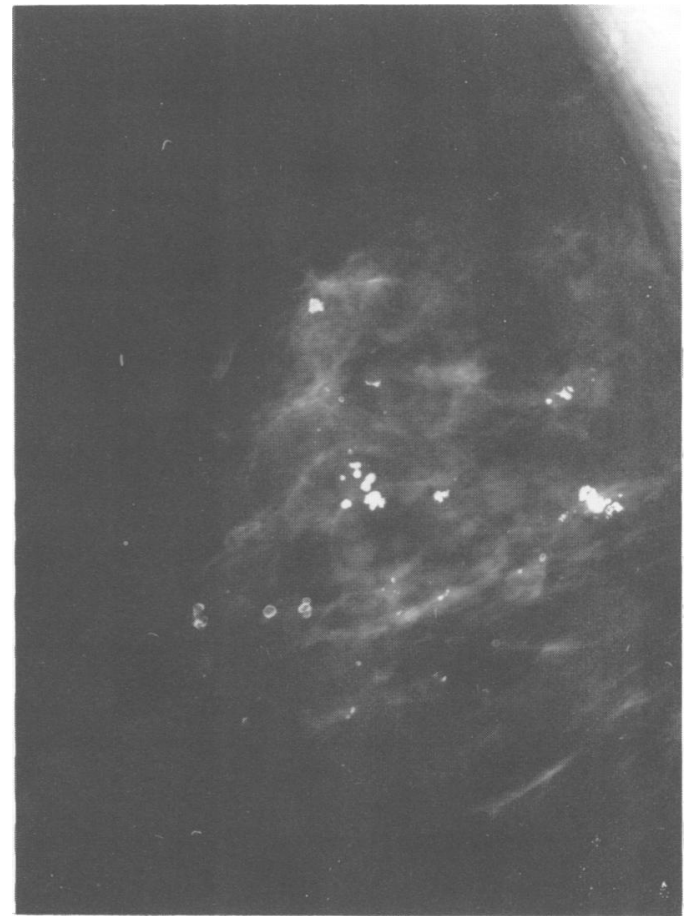

Figure 3 Mammograms of the proband's mother showing lesions consistent with fibroadenomas.

tumour suppressor gene was detected by $\sin _{5 \text { a }}$ strand conformational polymorphism (SSCP) analysis, using the most sensitive running conditions $^{9}$ for the $\mathrm{p} 53$ gene.

\section{Discussion}

There have been over 100 cases of Cowden syndrome reported in English publications to date, ${ }^{45}$ describing more than 50 abnormalities observed in patients with this phakomatosis. ${ }^{4}$ Since over $70 \%$ of these patients have mucocutaneous papillosis, acral keratoses, and breast disease in affected females (both malignant and benign), these features probably characterise Cowden syndrome. Thyroid disease (both benign and malignant), macrocephaly, gastrointestinal hamartomas, and gynaecological problems are believed to be part of the syndrome as well.

Lhermitte-Duclos disease is believed to be a hamartomatous overgrowth of hypertrophic ganglion cells which replace the granular cell layer and Purkinje cells of the cerebellum. ${ }^{7810}$ Clinically, LDD may manifest with ataxia, signs and symptoms of raised intracranial pressure, seizures, megencephaly, and mental retardation. ${ }^{78}{ }^{10-13}$ By 1992, 62 patients with LDD, without Cowden syndrome, had been described; interestingly, some of these patients have been noted to have breast or other cancers. ${ }^{7}$ In the family reported in this paper, the proband's grandfather (I.1) undoubtedly had LDD as the diagnosis was made by cerebellar biopsy. Although no cerebellar mass was noted in the proband's mother by magnetic resonance imaging, she has the signs of ataxia, megencephaly, seizures, and decreased IQ, 
which suggest the clinical diagnosis of LDD. Similarly, the proband has macrocephaly and mild mental retardation. We argue, therefore, that both the proband and her mother may actually have LDD by clinical criteria, although the classic pathognomonic anatomical signs are absent, and that Cowden syndrome and the clinical features of LDD appear to be coinherited in this family. In patients with LDD, the age that a cerebellar mass becomes evident on imaging studies is unknown. It may be prudent to follow the proband and her mother expectantly to determine if a classic cerebellar hamartoma, with attendant worsening cerebellar signs, will develop with age. In addition, this report calls attention to clinicians to consider the diagnosis of LDD in any patient with Cowden syndrome with megencephaly or macrocephaly, mental retardation, seizure disorder, or ataxia.

To date, there are four sporadic cases and three families with both Cowden syndrome and LDD (this report). ${ }^{7811-13}$ Both these conditions are of unclear aetiology. Given the rarity of both syndromes and the coincident occurrence of both Cowden syndrome and LDD in the four cases and three families, it seems plausible that both are related pathogenetically." Cowden syndrome and LDD appear to be coinherited in an autosomal dominant manner in some families, as illustrated by the three families ${ }^{11}$ (this report). Cowden syndrome is probably the result of a single, variably penetrant, autosomal dominant gene. The germline mutation in Cowden syndrome families with LDD may be different from that in families without LDD. The clinical features of Cowden syndrome also show intrafamilial variation, which may be the consequence of additional modifying genes. Consistent with this, variable expression of the LDD phenotypes in Cowden syndrome was observed in the two families described by Padberg et al. ${ }^{11}$

The location of the susceptibility gene(s) for Cowden syndrome and Lhermitte-Duclos disease is unknown. Cytogenetic studies have been unhelpful, and molecular genetic analyses have rarely been performed. Mutation analysis in RAS, HER2/neu, and pS2 genes have been performed in one patient with Cowden syndrome. ${ }^{1}$ No mutations were found in the DNA from this patient's breast tumours. The tumour suppressor gene p53 codes for a $53 \mathrm{kDa}$ phosphoprotein involved in cell cycle regulation and is believed to act as a transcription factor. ${ }^{14}$ Somatic p53 mutations are the commonest abnormalities in human cancer. ${ }^{15}$ Over $90 \%$ of p 53 mutations are found in exons 5-9. Germline p53 mutations have been described in patients with the Li-Fraumeni syndrome, which is a rare autosomal dominant syndrome of breast cancer, sarcoma, and other cancers involving all three germ layers. ${ }^{16-18} \mathrm{~A}$ survey of the constitutional p53 gene was undertaken in our family for two reasons. Firstly, a patient with multiple primary cancers and multiple tricholemmomata of the scalp (lesions seen in Cowden syndrome) has been previously described to have a $C$ to $T$ mutation in exon 8 of the p53 gene. ${ }^{19}$ Secondly, somatic p53 mutations and altered p53 expressions are found in skin tumours. ${ }^{2021}$ However, no germline p53 mutations were detected by SSCP analysis in the present family with both Cowden syndrome and LDD. Since SSCP analysis using the most sensitive running condition has a sensitivity of $90 \%$ to detect p53 mutations, ${ }^{9}$ there is a small possibility that an exonic mutation in the p53 gene was not detected. Other explanations, such as intronic mutations, are less likely as the great majority of known p53 mutations are found within exons $5-9 .{ }^{22}$ Therefore, to a $90 \%$ likelihood, we have excluded mutations in the entire p53 coding sequence as the aetiology of Cowden syndrome in this family. Other genes such as mdm-2 and WT1, whose products are known to interact with $\mathrm{p} 53,{ }^{23}{ }^{24}$ would be possible candidate genes.

Ideally, mutation analysis of p53 and other candidate genes should be performed in multiple families with Cowden syndrome. However, Cowden syndrome is rare. Thus, it may be prudent for an international collaborative effort both to define the clinical features of Cowden syndrome and to search for the susceptibility gene.

We thank Drs Albert Lin and Anil Rustgi for helpful discussions concerning the proband, Dr Michael Ronthal for discussions concerning the clinical diagnosis of Lhermitte-Duclo disease, Professor Kevin Burnand for sending copies of th clinical record of the proband's mother, and Dr Juliet Britton for review of the MRI. We are grateful to Dr Lois Mulligan and Professor Fred $\mathrm{Li}$ for their continued support and encouragement. C Eng is supported by the CRC Dana-Farber Cance Institute Fellowship at the University of Cambridge, B A J Ponder by a CRC Gibb Fellowship, and R A Eeles by the Clinical Research Committee of the Royal Marsden Hospital.

1 Willard W, Borgen P, Bol R, Tiwari R, Osbourne M Cowden's disease. A case report with analyses at th molecular level. Cancer 1992;69:2969-74.

2 Lloyd KM II, Denis M. Cowden's disease: a possible new symptom complex with multiple system involvement Ann Intern Med 1963;58:136-42.

3 Carlson GJ, Nivatvongs S, Snover DC. Colorectal polyps in Cowden's disease (multiple hamartomas syndrome). Am f Surg Pathol 1984;8:763-9.

4 Starink TM, van der JPW, Arwert F, et al. The Cowden syndrome: a clinical and genetic study in 21 patients. Clin Genet 1986;29:222-33.

5 Bagan JV, Penarrocha M, Vera-Sempere F. Cowden syndrome: clinical and pathological considerations in two new cases. Oral Maxillofac Surg 1989;47:289-294.

6 Guerin V, Bene MC, Judlin P, Beurey J, Landes, P, Faure G. Cowden disease in a young girl: gynaeologic and $\mathrm{G}$. Cowden disearview in a case and in the literature. Obstet Gynecol 1989;73:890-2.

7 Albrecht S, Haber RM, Goodman JC, Duvic M. Cowden syndrome and Lhermitte-Duclos disease. Cancer syndrome and

8 Russell Jones R, O'Brien M, Wells RS. Cowden's syndrome. Br f Dermatol 1981;105(suppl 19):57-8.

9 Condie A, Eeles RA, Borressen AL, Coles C, Cooper CS Condie A, Eeles RA, Borressen AL, Coles C, Cooper CS, Prosser J. Detection of point mutations in the p53 gene. Comparison of
1993;2:58-66.

10 Ambler M, Pogacar S, Sidman R. Lhermitte-Duclos disease (granule cell hypertrophy of the cerebellum). Pathoease (granule cell hypertrophy of the cerebellum). Patho-
logical analysis of the first familial cases. $\mathcal{f}$ Neuropathol logical analysis of the first

11 Padberg GW, Schot JDL, Vielvoye J, Bots GTAM, de Beer FC. Lhermitte-Duclos disease and Cowden disease: a FC. Lhermitte-Duclos disease and Cowden dis
single phakomatosis. Ann Neurol 1991;29:517-23.

12 King MA, Coyne TJ, Spearritt DJ, Boyle RS. LhermitteDuclos disease and Cowden syndrome: a third case. Ann Neurol 1992;32:112-13.

13 Williams DW III, Elster AD, Ginsberg LE, Stanton C. Recurrent Lhermitte-Duclos: report of two cases and association with Cowden's disease. Am f Neuroradio 1992;13;287-90

14 Mack DH, Vartikar J, Pipas JM, Laimins LA. Specific repression of TATA-mediated but not initiator-mediated transcription by wild-type p53. Nature 1993;363:281-3.

15 Hollstein MC, Sidransky D, Vogelstein B, Harris CC. p5 mutations in human cancers. Science 1991;253:49-53.

16 Malkin D, Li FP, Strong LC, et al. Germ line p 53 mutations in a familial syndrome of breast cancer, sarcomas, and other neoplasms. Science 1990;250:1233-8. 
17 Srivastava S, Zou Z, Pirollo K, Blattner, W, Chang EH. Germline transmission of a mutated p 53 gene in a cancerprone family with Li-Fraumeni syndrome. Nature prone family wit

18 Garber JE, Goldstein AM, Kantor AF, Dreyfus MG, Fraumeni JF Jr, Li FP. Follow-up study of twenty-four families with Li-Fraumeni syndrome. Cancer Re

19 Eeles RA, Warren W, Knee G, et al. Constitutional mutation in exon 8 of the p53 gene in a patient with multiple primary tumours: molecular and immunohistochemical

20 Ro YS, Cooper PN, Lee JA, et al. $\mathrm{p} 53$ protein expression in benign and malignant skin tumours. $\mathrm{Br} f$ Dermatol 1993;128:237-41.

21 Moles J-P, Moyret C, Guillot B, et al. p53 gene mutations in human epithelial skin cancers. Oncogene 1993;8:583-8. 22 Harris CC, Hollstein M. Clinical implications of the p53 tumor-suppressor gene. N Engl f Med 1993;329:1318-27. 23 Momand J, Zambetti GP, Olson DC, George DL, Levine AJ. The mdm-2 oncogene product forms a complex with the p53 protein and inhibits p53-mediated trans-activation. Cell 1992;69:1237-45.

24 Maheswaran S, Park S, Bernard A, et al. Physical and functional interaction between WT1 and p53 proteins. Proc Natl Acad Sci USA 1993;90:5100-4. 